\title{
Comparative Cost Benefit Analysis of Different Solid Waste Management Scenarios in Basrah, Iraq
}

\author{
Sherien Elagroudy ${ }^{1}$, Tamer Elkady ${ }^{2}$, Fikry Ghobrial ${ }^{1}$ \\ ${ }^{1}$ Sanitary and Environmental Section, Faculty of Engineering, Ain Shams University, Cairo, Egypt; ${ }^{2}$ Geotechnical Engineering Sec- \\ tion, Faculty of Engineering, Cairo University, Giza, Egypt. \\ Email: shereen_23@hotmail.com
}

Received March 2 ${ }^{\text {nd }}, 2011$; revised April 11 ${ }^{\text {th }}, 2011$; accepted May 20 $0^{\text {th }}, 2011$.

\begin{abstract}
Solid Waste Management (SWM) system in Basrah has deteriorated recently to the point that only limited waste collection is undertaken in certain urban areas and disposal is largely to uncontrolled dump sites. In this study, the technical, economical, and environmental aspects of three SWM scenarios were investigated aiming to compare the scenarios and select the most appropriate one for implementation. Scenario 1 was to consider waste disposal into a sanitary landfill. Scenario 2 added waste transportation to transfer station before disposal to a sanitary landfill. Scenario 3 considered waste sorting, recycling and composting followed by landfill disposal in an integrated treatment disposal facility. The current open dumping practice was considered as the baseline scenario. According to economic analysis, the benefits from the revenues of selling the produced recyclables and compost did not improve the ranking of scenario 3. However, scenario 3 has gained positive recognition due to the environmental benefits of waste recycling. Therefore, final recommendations were in favour of scenario 3, which has been approved by the UNICEF, as well. Currently the recommended scenario is under implementation in Basrah, Iraq.
\end{abstract}

Keywords: Cost-Benefit Analysis, Environmental Analysis, Economical Cost, Integrated SWM Plan

\section{Introduction and Methods}

Solid waste has been produced since the beginning of civilization. During the earliest periods, solid wastes were conveniently and unobtrusively disposed of in large open land spaces, as long as the density of the population was low. Nowadays, one of the consequences of global urbanization is an increased amount of solid waste. About $1.3 \times 10^{9}$ ton of municipal solid waste (MSW) was generated globally in 1990 [1], and, at present, the annual generation is approximately $1.6 \times 10^{9}$ ton.

The state of the economy influences waste generation [2]. Usually, greater economic prosperity and a larger urban population results in a larger amount of solid waste generation [3]. Improper disposal of waste impairs additional expenditure to fight the spread of communicable diseases and increase treatment cost to remove pollutants [4].

Poor MSW disposal and management systems are direct threats to nature and health [5,6]. Environmentally acceptable management of MSW has become a global challenge due to limited resources, an exponentially increasing population, rapid urbanization and worldwide industrialization. These factors are further exacerbated by inadequate financial resources, and management.

This century has witnessed a changing perspective in waste management, brought about primarily as an outcome of the initiation of the environmental movement in the 1970s. This new perspective holds that waste should be recovered or disposed of without jeopardizing human health and without using processes or methods which could harm the environment [7]. Linked with these ecological issues are concerns arising from the depletion of natural resources and the need for resources conservation. Hence, resource recovery is now firmly entrenched as a component of waste management strategies stimulating the development of comprehensive treatment and disposal approaches, and at the same time setting integrated waste management methods.

Integrated MSW disposal systems are not yet implemented in Iraq. The most common disposal methods currently are open dumping and burning in open spaces even 
in big cities, such as Basrah. Generally, the low-lying areas and outskirts of the towns and cities are used for this purpose. These practices have negative impacts on the environment and are socially unacceptable.

Several waste management and disposal methods are being used in various parts of the world and the most prominent of these are: open dumping, sanitary landfilling, composting, and recycling. Sanitary landfilling is a controlled engineered operation, designed and operated according to acceptable standards. It may be defined as a controlled method of disposing of refuse onto or into land while minimizing nuisances or hazards to public health or safety. The operation is carried out without environmental damage and in areas already spoiled or in need of restoration.

In contrast to a sanitary landfill, composting of refuse is an aerobic method of decomposing solid waste. Many types of microorganisms already present in the waste biostabilize the organic matter in the waste and produce a soil conditioner as a result of the process. The potential benefits of composting organic wastes are improved organic waste handling; reduced odor, fly, and other vector problems; and reduced weed seeds and pathogens. Composting organic materials reduces risk of leachate and other contaminants from polluting water resources. Land applied compost improves soil fertility, and water holding capacity. It is also free of offensive odors and can be stored for extended periods. These qualities make it suitable for use on farms or for sale.

Solid wastes contain significant amounts of recyclables like paper, plastics, glass and metals which, if they are recycled, and reused, would reduce the volume of the wastes to be collected and at the same time would yield significant salvage and resale income, and will help to save valuable natural resources and turn wastes into useful products.

Many studies have been reported on strategies to achieve municipal solid waste management [8-10]. A fundamental difficulty in planning a MSW management system is the need to simultaneously account for conflicting objectives. Planners must develop the best practicable and environmentally sustainable waste management strategies, which can be very difficult. The different objectives are not all related to economic costs, and must therefore be considered in a proper multi-objective framework. Generally speaking, the objectives are partly economic and partly environmental. This paper presents an approach that explicitly considers at least three aspects: financial affordability, environmental effectiveness and social acceptability. In Iraq, as in other developing countries, environmental considerations are not a priority in many decisions. The perception of managers is that it would be expensive if environmentally responsive me- thods are applied. Furthermore, existing environmental legislations do not have specific beneficial targets and are in the early stage of reform.

Methodologies for analyzing waste management systems or strategies include material flow analysis (MFA) [11], cost-benefit analysis (CBA) [12] and life cycle analysis (LCA) [13]. In this study, different scenarios for the management of solid waste management in Basrah City were considered and compared using (CBA) approach.

\section{Materials and Methods}

\subsection{Assessment of Current Solid Waste Management Scenarios in Basrah}

As part of this study, the current situation of the solid waste management in Basrah Governorate was assessed from the standpoints of waste generation, Solid Waste Management (SWM) facilities, equipment, personnel, recycling practices, and the overall institutional framework, including private sector participation.

More than $90 \%$ of MSW generated in Iraq is directly disposed on land in an unsatisfactory manner. The problem is already acute in cities and towns as disposal facilities have not been able to keep pace with the quantity of wastes generated. It is common to find large heaps of garbage lying in a disorganized manner in every nook and corner in large cities. Basrah, one of Iraq's largest metropolitan cities, like other large cities faces similar problems of poor solid waste management. The objective of this paper is to analyze some of the strengths and deficiencies in the current MSW management system in Basrah City, propose different SWM scenarios and perform a cost benefit analysis to select the most economically feasible scenario.

Estimates of urban solid waste generation rates and composition in Basrah Governorate were obtained from published reports on Solid waste management in Basrah City [14] and discussion with solid waste management officials. As verification, the reported waste generation rates were compared to that reported in the technical literature for low income and Middle Eastern countries.

Current estimate of solid waste generation rates in 2008 for Basrah City was estimated to be $0.85 \mathrm{~kg} / \mathrm{capita} /$ day. Future waste generation rates for basrah in the short, medium, and long terms are provided in Table 1. These rates have been estimated based on typical growth rates of solid waste generation reported for Middle Eastern Countries [15]. Adopting this growth rate, the waste generation rates, in the short, medium, and long term over the time horizon of the integrated solid waste management master plan (ISWMMP) are shown in Table 1. Using the generation rates given in Table 1, the amount of daily generated waste for Basrah City for the short, me- 
Table 1. Waste generation rates for short, medium, long term.

\begin{tabular}{lccc}
\hline $\begin{array}{l}\text { Waste Generation Rate } \\
\text { (Kg/capita/day) }\end{array}$ & Short Term & Medium term & Long term \\
\cline { 2 - 4 } & $(2009-2014)$ & $(2015-2019)$ & $(2020-2029)$ \\
\hline Basrah City & $0.85-1.02$ & $1.02-1.18$ & $1.18-1.58$ \\
Considered Figure & avg. 0.90 & avg. 1.10 & avg. 1.30 \\
$\begin{array}{l}\text { Average Annual } \\
\text { Generation Rate (ton/year) }\end{array}$ & 280,176 & 405,600 & 589,680 \\
\hline
\end{tabular}

dium and long term is calculated.

Information regarding solid waste stream composition was obtained from field sampling data as provided in Table 2. Based on Table 2, the percentage of Basrah City municipal solid waste stream consisting of materials which are considered to be recyclable or compostable is significant. Findings based on field data estimate recyclable or compostable material to be about $84 \%$. Although there is no data on waste composition for commercial and small to medium-sized industrial waste, it is anticipated that this waste will significantly contribute to the recyclable portion. This large percentage of recyclable/compostable material in the waste stream provides optimism that large-scale recycling and composting will be feasible and significantly reduce the volume of solid waste transferred to landfill.

Information regarding solid waste management practices in Basrah City, including inventory of sanitation equipment and vehicles, were based on data provided by relevant authorities and field verified using questionnaires. A brief description of current solid waste management operations are provided hereinafter.

Collection and transfer of solid waste in Basrah City is the responsibility of the municipality. Current solid waste management (SWM) operations in Basrah city rely on the stationary container system (common bins) and a fleet of mechanical equipment and vehicles that are owned by the municipalities. For this system, residents place their waste in bins that are located at central points throughout the city. Current deficiency in the number of bins distributed throughout the urban areas has resulted in waste filling the bins and accumulating around on streets. In addition to the formal sector, the informal sector plays a minor role in the collection and transfer of waste in some areas of the city of high income level. Waste is collected from household and they are transferred to open areas where they are manually recover salvageable material, that is then sold.

At the time of the study, no transfer stations were available in Basrah City. However, Basrah City has allocated land for which permits for the construction of two transfer stations at the southwestern and eastern boundaries of the Basrah City has been obtained. Furthermore,
Table 2. Composition of MSW as percentage of weight in Basrah city [14].

\begin{tabular}{cccc}
\hline Waste Components & Average (\%) & Waste Components & Average (\%) \\
\hline Organic waste & 66.6 & Rubber & 0.7 \\
Plastic & 6.4 & Textile & 2.7 \\
Incombustible & 9.4 & Combustible & 1.8 \\
Paper & 3.7 & Glass & 5.2 \\
Metal & 3.5 & & \\
\hline
\end{tabular}

no formal solid waste treatment and processing facilities was identified for Basrah City.

Basrah city had a designated waste disposal area located outside the urban limits of the city. However, this site was not built, operated, or managed to any acceptable standards and generally classified as open dumpsite.

Assessment of the current solid waste management (SWM) situation in Basrah City revealed the following features:

- Waste collection, transport, and disposal systems operate at reduced capacities due to civil unrest, looting of SWM facilities and equipment, lack of maintenance, and insufficient numbers of qualified SWM managers, supervisors, and specialist personnel. Results include substantial waste accumulations around public waste containers and in streets and public areas.

- There are no sanitary landfills and most of the dumpsites in Basrah City are at the limits of their capacity to accept wastes.

- There is an informal recycling economy, although its size is difficult to estimate. Materials are provided by informal waste collectors who engage in door-to-door collection from higher-income neighborhoods and sort the dry wastes. Small enterprises buy these materials, perform some levels of processing, and sell them to end-users.

- Composting of urban wet wastes does not appear to be practiced.

\subsection{Integrated Solid Waste Management Master Plan}

In an attempt to improve public and environmental health in Basrah City provisions were taken for the development of an integrated solid waste management Master Plan (ISWMMP). This plan will be implemented for a time horizon of 20 years divided into three terms; Short Term (2009-2014), Medium Term (2015-2019), and Long Term (2020-2029). Construction and organization of SWM activities will be implemented in phases, with specific activities and geographic areas receiving improved service over the three periods of the Master Plan. As part of this ISWMMP, different scenarios for the 
management of solid waste management in Basrah City were considered and compared using Cost-Benefit Analysis approach (CBA). Overall targets for the SWM organization in Basrah City in the short, medium, and long term are summarized in Table $\mathbf{3}$.

\subsection{Development of Scenarios}

In this study, the scenarios shown in Figure 1 have been developed (Figure 1) for the management of solid waste generated in Basrah City through out the 20 years time horizon. The current solid waste operation of waste collection and disposal in open dumping was included as the baseline scenario (Scenario 0) for comparison. All scenarios use the same method, equipment, and human labor for waste collection and transportation. The other three scenarios are:

Scenario 1:

Waste is collected using collection bins, transported in trucks and then disposed in a landfill that is located inside the boundaries of Basrah City. No transfer station stations were considered in this case.

Scenario 2:

Landfill site allocated for waste disposal is located outside the limits of Basrah City and at a distance of approximately $40 \mathrm{~km}$ from the City center. A transfer station (TS) is constructed where waste is unloaded from small

Table 3. Targets for SWM organization in Basrah city over ISWMMP time horizon.

\begin{tabular}{lll}
\hline \multicolumn{1}{c}{ Short Term } & \multicolumn{1}{c}{ Medium Term } & \multicolumn{1}{c}{ Long Term } \\
\hline $\begin{array}{l}\text { Restore an efficient and } \\
\text { operational waste collection } \\
\text { system in Basrah City to } \\
\text { achieve a target collection } \\
\text { rate not less than 80\%. }\end{array}$ & $\begin{array}{l}\text { efficiency to not } \\
\text { less than 85\% }\end{array}$ & $\begin{array}{l}\text { Increase collection } \\
\text { efficiency to not less } \\
\text { than 90\% }\end{array}$ \\
$\begin{array}{l}\text { Initiate sanitary disposal in } \\
\text { Basrah City }\end{array}$ & $\begin{array}{l}\text { Construction and operation of an } \\
\text { integrated treatment, disposal facility } \\
\text { for Basrah City (ITDF) }\end{array}$ \\
\hline
\end{tabular}

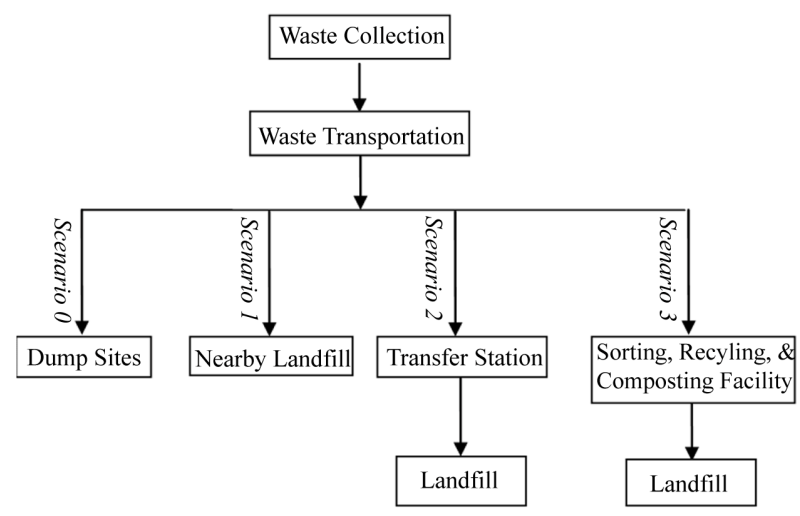

Figure 1. Scenarios considered during study. collection vehicles and then reloaded onto larger, longdistance transport vehicles for shipment to landfill.

Scenario 3:

Waste collected from Basrah city is transported via TS to integrated treatment and disposal facility (ITDF). The facility is designed to receive municipal solid waste, where recyclable materials are separated manually and made ready for either bale \& sell, or recycled in new plants in the future phases of the project for reuse in safe industries.

A graphical illustration of the proposed scenarios is shown in Figure 1. Waste material flow inventory for each of the proposed solid waste management scenarios in the short, medium, long term is provided in Table 4.

\subsection{Cost-Benefit Analysis}

Cost estimates for the SWM scenarios include capital costs and operation and maintenance (O\&M) costs. The capital cost is the sum of civil works cost and mechanical equipment cost. Operation cost is represented by the annual expenditure for power, fuel, and labor. Maintenance cost is taken as a percentage of the capital cost.

The objective of cost estimates in this study is mainly to serve the cost benefit analysis and recommendations that will follow. The capital as well as O\&M costs are determined as a function of the yearly MSW generation.

Estimated capital and O\&M costs up to year 2029 are carried out for all considered SWM scenarios on spreadsheets in response to short term, medium term and long term needs. A comparative life cycle costing (LCC) analysis has been applied to identify the least cost scenario. The analysis of alternative Master Plan scenarios has considered economical, environmental and social aspects to the greatest extent possible.

Minimum cost is one of the criteria to select the most economical scenario. However, environmental impacts and benefits may divert the recommendations towards sustainability, which is currently more desired by societies seeking long term environmental benefits and conserving natural air, water and soil resources.

The LCC analysis has been conducted based on the following assumptions:

1) An infinite horizon is assumed. This time frame is used in order to account for the different service times of the facilities and/or equipment.

2) Capital and O\&M costs are discounted at a constant interest rate of $10 \%$.

3) Basically the total cost of a SWM scenario on an infinite horizon consists of 1 ) the total discounted capital cost and 2) the total discounted O\&M cost.

The total present worth capital cost $\left(P_{c}\right)$ assuming replacement of units every $n_{e}$ year is given by: 
Table 4. Waste material flow inventory for proposed SWM scenarios.

\begin{tabular}{|c|c|c|c|c|c|c|}
\hline & \multirow[b]{2}{*}{ Scenario } & \multirow{2}{*}{$\begin{array}{l}\text { Recycling } \\
\text { (ton/year) }\end{array}$} & \multirow{2}{*}{$\begin{array}{l}\text { Composting } \\
\text { (ton/year) }\end{array}$} & \multicolumn{3}{|c|}{ Disposal } \\
\hline & & & & $\begin{array}{l}\text { Dumpsite } \\
\text { (ton/year) }\end{array}$ & $\begin{array}{l}\text { Sanitary landfilling } \\
\text { (ton/year) }\end{array}$ & $\begin{array}{l}\text { Sanitary landfilling via TS } \\
\text { (ton/year) }\end{array}$ \\
\hline \multirow{3}{*}{0} & Short Term & -- & -- & 280,176 & -- & -- \\
\hline & Medium Term & -- & -- & 405,600 & -- & -- \\
\hline & Long Term & -- & -- & 589,680 & -- & -- \\
\hline \multirow{3}{*}{1} & Short Term & -- & -- & 280,176 & -- & -- \\
\hline & Medium Term & -- & -- & -- & 405,600 & -- \\
\hline & Long Term & -- & -- & -- & 589,680 & -- \\
\hline \multirow{3}{*}{2} & Short Term & -- & -- & 280,176 & -- & -- \\
\hline & Medium Term & -- & -- & -- & -- & 405,600 \\
\hline & Long Term & -- & -- & -- & -- & 589,680 \\
\hline \multirow{3}{*}{3} & Short Term & -- & -- & 280,176 & -- & -- \\
\hline & Medium Term & 73,414 & 246,605 & -- & -- & 85,581 \\
\hline & Long Term & 106,732 & 358,525 & -- & -- & 124,423 \\
\hline
\end{tabular}

$$
P_{c}=\sum_{k=0}^{k-1}\left(\frac{1}{1+i}\right)^{L_{k}}\left[I_{c k} /\left(1-\frac{1}{(1+i)^{n_{e}}}\right)\right]
$$

where;

$P_{c}$ : Total present worth of all capital costs

$i$ : Interest rate (\%)

$L_{k}$ : The difference between the time of adding new cost element $(k)$ and the year of estimating the cost

$I_{c k}$ : Initial capital cost of element $(k)$ brought to its worth

$n_{e}$ : Expected life time of equipment, in years

The following input parameters have been used in the LCC analysis:

Life time of collection equipment $=5$ years

Life time of cleansing and beautification equipment $=$ 10 years

Life time of transfer equipment $=10$ years

Life time of transfer station equipment $=20$ years

Life time of treatment facility equipment $=15$ years

Life time of disposal facility equipment $=20$ years

Similarly, the present worth of O\&M costs $\left(O M_{c}\right)$ is given by:

$$
O M_{c}=\sum_{k=0}^{k-1}\left(\frac{1}{1+i}\right)^{L_{k}}\left[\frac{O M_{k}}{i(1+i)}\right]
$$

Where;

$O M_{k}$ : Annual O\&M payments starting the year of the new added element $(k)$.

The total present worth of capital and O\&M costs $\left(T_{c}\right)$ is obtained by summing Equations (1) and (2) to yield:

$$
T_{c}=P_{c}+O M_{c}
$$

\subsection{Environmental Assessment of Proposed Scenarios}

Research has revealed that there is no preferred solid waste management system with respect to environmental performance. However, the anticipated environmental impacts depend on several factors such as characteristics and composition of waste, the efficiency of the waste collection and processing systems required by different waste management practices, emissions from waste management facilities, end use of the materials recovered from the waste stream, and the availability and proximity of markets for recovered materials.

A life cycle environmental performance of each proposed ISWM scenarios for Basrah City was performed. Analysis was performed using the Environmental Analysis Model (EAM) developed by Corporations Supporting Recycling (CSR) and the Environment and Plastics Industry Council. The EAM model uses a life cycle approach to evaluate the environmental burdens associated with waste management elements (i.e., collection, transfer, sorting, recycling, composting, energy recovery, and landfilling) from the point at which a material is discarded into the waste stream to the point at which it is either converted into a resource (such as recycled material or recovered energy) or, it is finally disposed. Specific burdens considered by EAM include estimates of the energy consumed (or produced) and the emissions to air, water and land associated recycling, composting, energy from waste and landfilling. The environmental parameters evaluated by EAM are part of the results of the 
analysis.

Input to the EAM model included waste generation quantities, waste composition for Basrah City as well as the anatomy of the proposed solid waste management scenarios in each term. It should be noted that short term SWM is identical for all proposed scenarios.

\section{Results and Discussion}

\subsection{Cost Benefit Analysis}

Estimated capital and O\&M costs up to year 2029 were carried out. A comparative life cycle costing (LCC) analysis has been applied to identify the least cost scenario. The analysis of alternative Master Plan scenarios has considered economical, environmental and social aspects to the greatest extent possible. The present worth of capital and O\&M costs for the considered scenarios on the short, medium, and long terms are given in Table 5. The economic comparison and least cost ranking of the considered scenarios are presented in Table 6.

Scenario 3 is the only scenario that has added value as benefits from marketing the produced recyclables and compost in the treatment facility. Therefore, benefits have been estimated for scenario 3, assuming that the produced compost will be sold at a price of $\$ 20$ per ton. The discounted revenues from selling this product have been subtracted from the present worth (PW) of O\&M costs to obtain the net PW O\&M costs, as shown in Table 7.

The benefits from the revenues of selling the produced compost did not improve the ranking of scenario 3 from the economical point of view. Only $0.4 \%$ of total cost was reduced due to the benefits gained from selling the recyclables and the compost. However, the environmental aspects have gained positive recognition of this alternative as it is presented hereafter.

\subsection{Environmental Assessment of Proposed Scenarios}

The life cycle environmental performance of each proposed scenario was performed using the Environmental Analysis Model (EAM). Tables 8 and 9 summarize the inventory of environmental parameters and the life cycle environmental performance for each proposed solid waste management scenario in the medium and long term. Results revealed that Scenario 3 provides the best environmental improvement represented by least burdens. Specifically, Scenario 3 provided performance improvement in 9 out of the 18 environmental burdens.

In conclusion, the net life cycle inventories for proposed solid waste management scenarios indicates that Scenario 3 provides significant improvement in all environmental parameters due to the diversion of waste to recycling.

Table 5. Present worth of capital and O\&M costs for the scenarios (costs are in US\$).

\begin{tabular}{cccccc}
\hline Project phases & & Scenario0 & Scenario1 & Scenario 2 & Scenario 3 \\
\hline \multirow{2}{*}{ Short Term } & PW Capital & 45074388 & 50660874 & 40222219 & 42701835 \\
& PW O\&M & 62450366 & 63657544 & 67299752 & 70159330 \\
& Sub-total & 10752474 & 11431848 & 107521971 & 112861165 \\
& PW Capital & 9236518 & 31192301 & 31829485 & 58708009 \\
Medium Term & PW O\&M & 76238349 & 78925003 & 85770546 & 115734280 \\
& Sub-total & 85474867 & 11011734 & 117600031 & 174442289 \\
& PW Capital & 39655477 & 13862517 & 85021118 & 108175402 \\
Long Term & PW O\&M & 11939990 & 12265518 & 134843634 & 183910985 \\
& Sub-total & 15905547 & 26128025 & 219864752 & 292086387 \\
\hline
\end{tabular}

Table 6. Economic comparison and least cost ranking of scenarios (costs are in US\$).

\begin{tabular}{ccccc}
\hline Scenario & PW Total Capital & PW Total O\&M & PW Total & Least Cost Ranking \\
Scenario 0 & 93966383 & 258088675 & 352055058 & 1 \\
Scenario 1 & 220478342 & 265237665 & 485716007 & 3 \\
Scenario 2 & 157072822 & 287913932 & 444986754 & 2 \\
Scenario 3 & 209585246 & 369804595 & 579389841 & 4 \\
\hline
\end{tabular}


Table 7. Influence of benefits on total cost of scenario 3 (costs are in US\$).

\begin{tabular}{cccc}
\hline & \multicolumn{3}{c}{ Scenario 3 } \\
\cline { 2 - 4 } & Short Term & Medium Term & Long Term \\
\hline PW Capital & 42701835 & 58708009 & 108175402 \\
PW O\&M & 70159330 & 115734280 & 183910985 \\
Sub-total PW Capital + O\&M & 112861165 & 174442289 & 292086387 \\
Sub-total Revenues & 196902.9 & 205605.2 & 597683.9 \\
Sub-total PW Revenues & 317114 & 331129 & 1550238 \\
Net PW O\&M & 69842216 & 115403151 & 182360747 \\
Sub-total PW Capital+ Net O\&M & 112544051 & 174111160 & 290536149 \\
Total with Benefits & & 577191360 & 579389841 \\
Total without Benefits & & &
\end{tabular}

Table 8 Inventory of environmental parameters for the proposed solid waste management scenarios.

\begin{tabular}{|c|c|c|c|c|c|c|c|c|c|}
\hline \multirow{2}{*}{ Parameter } & \multirow{2}{*}{ Unit } & \multicolumn{2}{|c|}{ Scenario 0} & \multicolumn{2}{|c|}{ Scenario 1} & \multicolumn{2}{|c|}{ Scenario 2} & \multicolumn{2}{|c|}{ Scenario 3} \\
\hline & & $\begin{array}{c}\text { Medium } \\
\text { Term }\end{array}$ & $\begin{array}{l}\text { Long } \\
\text { Term }\end{array}$ & $\begin{array}{l}\text { Medium } \\
\text { Term }\end{array}$ & $\begin{array}{l}\text { Long } \\
\text { Term }\end{array}$ & $\begin{array}{l}\text { Medium } \\
\text { Term }\end{array}$ & $\begin{array}{l}\text { Long } \\
\text { Term }\end{array}$ & $\begin{array}{l}\text { Medium } \\
\text { Term }\end{array}$ & $\begin{array}{l}\text { Long } \\
\text { Term }\end{array}$ \\
\hline Quantity of Waste & $t * 10^{5}$ & 4.05 & 5.896 & 4.05 & 5.896 & 4.05 & 5.896 & 4.05 & 5.896 \\
\hline Energy Consumed & $\mathrm{GJ} * 10^{3}$ & 3.45 & 4.54 & 19.8 & 28.4 & 23.3 & 33.4 & 127 & 212.82 \\
\hline$-\mathrm{CO}_{2}$ & $t^{*} 10^{3}$ & 0.28 & 0.37 & 1.75 & 2.5 & 1.99 & 2.87 & 11 & 19 \\
\hline$-\mathrm{CH}_{4}$ & $t^{*} 10^{3}$ & 15.7 & 22.78 & 15.67 & 22.8 & 15.67 & 22.78 & 0.46 & 0.055 \\
\hline - $\mathrm{CO}_{2}$ Equivalents & $t^{*} 10^{3}$ & 3.29 & 4.79 & 3.32 & 4.8 & 3.32 & 4.83 & 0.27 & 0.31 \\
\hline - Nox & $\mathrm{t}$ & 1 & 1.16 & 4 & 5.6 & 6 & 8.71 & 22 & 35.5 \\
\hline - Sox & $\mathrm{t}$ & 2 & 2.59 & 13 & 19.2 & 14 & 19.96 & 91 & 152.98 \\
\hline - HC1 & $\mathrm{t}$ & 1 & 2.06 & 1 & 2.1 & 1 & 2.08 & 0 & 0.2 \\
\hline - Nox & $\mathrm{t}$ & 1 & 1.16 & 4 & 5.6 & 6 & 8.71 & 22 & 35.5 \\
\hline - PM & $t^{*} 10^{2}$ & 1.1 & 1.59 & 1.11 & 1.6 & 1.11 & 1.61 & 0.95 & 1.37 \\
\hline - VOCs & $\mathrm{t}$ & 49 & 70.44 & 51 & 74.7 & 52 & 76.01 & 29 & 45.43 \\
\hline $\mathrm{Pb}$ in Air & Kg & 0 & 0.31 & 1 & 1.3 & 1 & 1.29 & 5 & 8.99 \\
\hline Hg in Air & $\mathrm{Kg}$ & 0 & 0 & 0 & 0 & 0 & 0.01 & 0 & 0.05 \\
\hline Cd in Air & Kg & 0 & 0.19 & 0 & 0.3 & 0 & 0.3 & 1 & 0.96 \\
\hline Dioxins (TEQ) in Air & G & 0 & 0.01 & 0 & 0 & 0 & 0.01 & 0 & 0 \\
\hline $\mathrm{Pb}$ in Water & $\mathrm{Kg}$ & 11 & 15.4 & 4 & 5.3 & 4 & 5.38 & 3 & 4.62 \\
\hline Hg in Water & Kg & 0 & 0.22 & 0 & 0.1 & 0 & 0.12 & 0 & 0.05 \\
\hline Cd in Water & Kg & 15 & 22.1 & 5 & 7.2 & 5 & 7.23 & 2 & 3.31 \\
\hline BOD in Water & $\mathrm{Kg} * 10^{4}$ & 20.2 & 2.94 & 3.84 & 5.6 & 3.84 & 5.58 & 1.71 & 2.37 \\
\hline Dioxins (TEQ) in Water & g & 0 & 0 & 0 & 0 & 0 & 0 & 0 & 0 \\
\hline Residual Waste & $t^{*} 10^{4}$ & 40.5 & 58.96 & 40.5 & 58.96 & 40.5 & 58.96 & 17.5 & 24.1 \\
\hline
\end{tabular}


Table 9. Life cycle environmental performance for the proposed solid waste management scenarios.

\begin{tabular}{|c|c|c|c|c|c|c|c|c|c|}
\hline \multirow[b]{2}{*}{ Parameter } & \multirow[b]{2}{*}{ Unit } & \multicolumn{2}{|c|}{ Scenario 0} & \multicolumn{2}{|c|}{ Scenario 1} & \multicolumn{2}{|c|}{ Scenario 2} & \multicolumn{2}{|c|}{ Scenario 3} \\
\hline & & $\begin{array}{c}\text { Medium } \\
\text { Term }\end{array}$ & $\begin{array}{l}\text { Long } \\
\text { Term } \\
\end{array}$ & $\begin{array}{c}\text { Medium } \\
\text { Term }\end{array}$ & $\begin{array}{l}\text { Long } \\
\text { Term }\end{array}$ & $\begin{array}{c}\text { Medium } \\
\text { Term }\end{array}$ & $\begin{array}{l}\text { Long } \\
\text { Term }\end{array}$ & $\begin{array}{c}\text { Medium } \\
\text { Term }\end{array}$ & $\begin{array}{l}\text { Long } \\
\text { Term } \\
\end{array}$ \\
\hline Energy Consumed & $\mathrm{GJ} * 10^{3}$ & 3.44 & 4.53 & 19.85 & 28.39 & 23.3 & 33.41 & $-1,118.0$ & $-2,276$ \\
\hline - CO2 & $\mathrm{t}^{*} 10^{3}$ & 0.28 & 0.37 & 1.76 & 2.52 & 2 & 2.87 & -39.1 & -76.47 \\
\hline - $\mathrm{CH} 4$ & $\mathrm{t}^{*} 10^{3}$ & 15.67 & 22.78 & 15.67 & 22.78 & 15.67 & 22.79 & -0.021 & -0.90 \\
\hline -CO2 Equivalents & $\mathrm{t}^{*} 10^{3}$ & 3.29 & 4.79 & 3.32 & 5 & 3.33 & 4.84 & -0.91 & -1.91 \\
\hline - Nox & $\mathrm{t}$ & 1 & 1 & 4.07 & 6 & 6.19 & 8.7 & -177.76 & -333 \\
\hline - Sox & $\mathrm{t}$ & 1.83 & 3 & 13.27 & 19 & 13.78 & 20 & -225.9 & -410 \\
\hline - HC1 & $\mathrm{t}$ & 1.42 & 2 & 1.43 & 2 & 1.43 & 2.1 & -2225.79 & $-3,642$ \\
\hline - Nox & $\mathrm{t}$ & 1 & 1 & 4.07 & 6 & 6.19 & 8.7 & -177.76 & -333 \\
\hline - PM & $\mathrm{t}^{*} 10^{2}$ & 1.09 & 1.59 & 1.11 & 1.61 & 1.11 & 1.61 & 0.27 & -0.02 \\
\hline $\mathrm{Pb}$ in Air & $\mathrm{Kg}$ & 0.21 & 0 & 0.88 & 1 & 0.89 & 1.3 & -3.73 & -5.3 \\
\hline $\mathrm{Hg}$ in Air & $\mathrm{Kg}$ & 0 & 0 & 0.01 & 0 & 0.01 & 0 & -0.3 & -0.6 \\
\hline Cd in Air & $\mathrm{Kg}$ & 0.13 & 0 & 0.2 & 0 & 0.21 & 0.3 & 0.27 & 0.4 \\
\hline Dioxins (TEQ) in Air & G & 0.01 & 0 & 0.01 & 0 & 0.01 & 0 & 0 & 0 \\
\hline $\mathrm{Pb}$ in Water & $\mathrm{Kg}$ & 10.6 & 15 & 3.66 & 5 & 3.7 & 5.4 & -36.28 & -58 \\
\hline Hg in Water & $\mathrm{Kg}$ & 0.15 & 0 & 0.08 & 0 & 0.08 & 0.1 & 0.09 & 0.2 \\
\hline Cd in Water & $\mathrm{Kg}$ & 15.22 & 22 & 4.97 & 7 & 4.97 & 7.2 & 1.39 & 2.1 \\
\hline BOD in Water & $\mathrm{Kg}^{*} 10^{4}$ & 20.2 & 29.41 & 3.84 & 5.59 & 3.84 & 5.59 & 2.37 & 4 \\
\hline Dioxins (TEQ) in Water & g & 0 & 0 & 0 & 0 & 0 & 0 & 0 & 0 \\
\hline Residual Waste & $\mathrm{t}^{*} 10^{4}$ & 40.56 & 58.96 & 40.56 & 58.96 & 40.56 & 58.96 & 17.58 & 24.1 \\
\hline
\end{tabular}

\section{Conclusions}

In this study, the technical, economical, and environmental aspects of different SWM scenarios were investigated to compare the options available for MSW management in Basrah City, Iraq. Three scenarios were compared namely; direct waste disposal into a sanitary landfill, waste transportation to transfer station and then to a sanitary landfill, sorting, recycling and composting followed by landfill disposal in an integrated treatment disposal facility. In addition, the current open dumping practice was included as the baseline scenario.

The benefits from the revenues of selling the produced recyclables and compost did not improve the ranking of scenario 3 from the economical point of view. However, the environmental aspects have gained positive recognition of scenario 3 due to the diversion of waste to recycling. Therefore, final recommendations favour scenario 3 which has been approved by the UNICEF, as well. Currently the recommended ISWMMP scenario is under implementation in Basrah, Iraq.

\section{Acknowledgements}

The Authors wish to thank University of Waterloo, Cana- da for providing the Integrated Waste Model (IWM).

\section{REFERENCES}

[1] D. N. Beede and D. E. Bloom, "The Economics of Municipal Solid Waste,” World Bank Research Observer, Vol. 10, No. 2, 1995, pp. 113-150. doi:10.1093/wbro/10.2.113

[2] J. Petts and G. Edulijee, "Environmental Impact Assessment for Waste Treatment and Disposal Facilities,” John Wiley and Sons, Hoboken, 1994.

[3] S. Chattopadhyay, et al., "Municipal Solid Waste Management in Kolkata, India-A Review," Waste Management, Vol. 29, No. 4, April 2009, pp. 1449-1458.

[4] T. W. Assmuth and T. Strandberg, "Ground Water Contamination in Finished Landfill," Water Air and Soil Pollution Journal, Vol. 69, No. 1-2, 1993, pp. 179-199. doi:10.1007/BF00478358

[5] J. Dotreppe and P. Grisaron, "Industrial and Urban MSW: Treatment, Destruction and Valorisation,” Publisher, Cebedoc Liège, 1986.

[6] L. Y. Mayster and V. Duflon, "Urban Wastes, Nature and Characterization,” Polytechnic and University Publisher Press, Lausanne, 1994.

[7] G. Tchobanoglous, H. Theisen and S. Vigil, "Integrated Solid Waste Management,” McGraw-Hill, New York, 
1993.

[8] S. Pawan, P. Sikka, R. C. Maheshwari and P. Chaturvedi, "Management of Municipal Solid Waste, Bio Energy for Rural Energization,” Department of Science and Technology, IIT, New Delhi, 1997, pp. 205-209.

[9] J. A. Salvato, “Solid Waste Management," Environmental Engineering and Sanitation," 4th Edition, Wiley, Hoboken, 1992, pp. 662-766.

[10] V. Kum, A. Sharp and N. Harnpornchai, "Improving the Solid Waste Management in Phnom Penh City: A Strategic Approach,” Waste Management Journal, Vol. 25, No. 1, 2005, pp. 101-109.

doi:10.1016/j.wasman.2004.09.004

[11] P. Brunner and H. Rechberger, "Practical Handbook of Material Flow Analysis, Series: Advanced Methods in Resource and Waste Management,” Vol. 1, CRC/Lewis
Publishers, 2003, p. 336.

[12] S. Farrow and M. Toman, "Using Benefit-Cost Analysis to Improve Environmental Regulations," Environment, Vol. 41, No. 2, 1999, pp. 12-21.

[13] R. G. Hunt, "Life Cycle Assessment Considerations of Solid Waste Management Alternatives for Papers and Plastics,” Resources Conservation \& Recycling, Vol. 14, No. 3-4, 1995, pp. 225-231. doi:10.1016/0921-3449(95)00018-E

[14] United Nations Environmental Programme (UNEP), "Solid Waste Management in Southern Governorates of Iraq,” September 2007.

[15] Regional Solid Waste Management Project in Mashreq and Maghreb Countries Prepared in collaboration with the International Consortium (ERM/GTZ/GKW) \& the Regional Management Group-ANPE, January 2004. 